\title{
Treatment of Primary Open-Angle Glaucoma and Ocular Hypertension with Preservative-Free Tafluprost-Timolol Fixed-Dose Combination Versus Preservative-Free Latanoprost-Timolol Fixed-Dose Combination Therapy: Real-World Experience
}

Ulrich Thelen ( $\square$ doceye1966@gmx.de)

Westfälische Wilhelms-Universität Münster: Westfalische Wilhelms-Universitat Munster https://orcid.org/0000-0002-9365-4841

\section{Research Article}

Keywords: Glaucoma, intraocular pressure (IOP), latanoprost, tafluprost, timolol

Posted Date: November 30th, 2021

DOI: https://doi.org/10.21203/rs.3.rs-1100928/v1

License: (c) (1) This work is licensed under a Creative Commons Attribution 4.0 International License.

Read Full License

Version of Record: A version of this preprint was published at Journal of Ophthalmology and Research on January 1st, 2022. See the published version at https://doi.org/10.26502/fjor.2644-00240054. 


\section{Abstract}

Background: To evaluate the effect of an "escalation" of topical glaucoma therapy by switching form prostaglandin monotherapy to two different prostaglandin-timolol fixed combinations.

Methods: 30 patients (60 eyes) with primary open-angle glaucoma (POAG) or ocular hypertension (OHT) were initially treated with the prostaglandin analog latanoprost in a preservative-free formulation. 15 patients each were for 6 months - because of IOP levels considered still too high - treated with preservative-free tafluprost/timolol fixed-dose combination or preservative-free latanoprost/timolol fixeddose combination therapy.

Results: Six months after switching from latanopost monotherapy to preservative-free prostaglandintimolol combinations, patients being treated with the latanoprost-timolol fixed combination had a mean IOP reduction by $4.16 \mathrm{~mm} \mathrm{Hg}$ and those treated with the tafluprost-timolol fixed combination a mean IOP reduction by $5.38 \mathrm{~mm} \mathrm{Hg}$. Regarding safety and tolerability, there were no issues in the tafluprost-timolol group.

Conclusions: Switching from prostaglandin monotherapy to a prostaglandin-timolol fixed combination led to a sufficient IOP lowering in our group of patients. Tolerability of, and satisfaction with, the fixed combination therapies was high.

\section{Introduction}

In daily ophthalmological practice, administering a topical antiglaucomatous drug to reduce intraocular pressure (IOP) usually is the first step in treating a patient with glaucoma. The class of IOP-lowering drugs chosen for initial glaucoma therapy depends on a number of factors, one of which may sometimes be the local or national health care system and its requirements. For example, in countries with tight health care budgets, the veteran drug pilocarpine is still regularly prescribed (1). From the 1970s to the mid-1990s, betablockers have usually been the first-choice drug, with timolol as the pioneering substance. Currently, prostaglandin analogues are widely considered the ideal drug for initial pharmacological glaucoma therapy in the industrialized world.(2)

If monotherapy turns out to be insufficient to achieve "target pressure" (the IOP level which is considered necessary to prevent further progression), the ophthalmologist will - based on his or her own experience and in accordance with the guidelines of societies like the European Glaucoma Society (EGS) - initiate a combination therapy, consisting of (at least) two different IOL-lowering drugs, preferably with different mechanisms of action, such as an outflow-enhancing substance combined with a drug that reduces aqueous humor production. In daily practice, a fixed combination of two antiglaucomatous drugs has proven to be preferable to have the patient handle two or more ophthiols, in particular with regard to patient adherence. (3) (4) Alternatives for such an "escalation" of therapy as described in the guidelines are, among others, selective laser trabeculosplasty (SLT) and the new minimally-invasive surgical techniques known as MIGS. (5) 
The aim of this retrospective study from a routine ophthalmological practice was to evaluate the effect of a change from prostaglandin monotherapy to a fixed combination of a prostaglandin and the betablocker timolol and to examine whether there are any differences in efficacy - i.e. lowering of IOP between two of such commonly prescribed combinations. It is a situation that ophthalmologists in the "real world" frequently face - to climb a step on the ladder of therapeutic options according to the EGS guidelines. The treatment's choice of the patients was not based on some study plan but on the ophthalmologist's expertise and experience; all substances involved had been approved for many years.

\section{Methods}

In our practice, 30 patients (60 eyes) with primary open-angle glaucoma (POAG) or ocular hypertension $(\mathrm{OHT})$ were initially treated with the prostaglandin analog latanoprost preservative-free (Monoprost ${ }^{\circ}$ ), applied once daily before nighttime. When the IOP under therapy was $18 \mathrm{~mm} \mathrm{Hg}$ and higher and/or the attending ophthalmologist regarded IOP values under this monotherapy not sufficiently lowered to prevent progression (in eyes with POAG) or the manifestation of initial glaucomatous damage to the optic disc, the retinal nerve fiber layer or the visual field (in eyes with $\mathrm{OHT}$ ), the patients were switched from mono- to combination therapy. 15 patients were treated with a preservative-free fixed combination of latanoprost and timolol (Fixaprost $\left.{ }^{\circ}\right)(6), 15$ patients with a preservative-free fixed combination of tafluprost and timolol (Taptiqom $\left.{ }^{\circ}\right)(7)(8)$.

The main outcome measure was the reduction in IOP that could be achieved by such a conversion of therapy. The patients were re-examined every four weeks over six months. To prevent an influence of the well-known circadian fluctuations of IOP, the measurements were always performed at an identical time of day. At the end of the study period, the patients were asked to assess the tolerability of the combination therapy.

\section{Results}

The 15 patients (30 eyes) who switched from latanoprost to the latanoprost-timolol fixed combination had an average age of 64.7 years, the 15 patients (30 eyes) who switched from latanoprost to the tafluprost-timolol fixed combination had an average age of 65.1 years. Under monotherapy, almost all IOP values were between $17 \mathrm{~mm} \mathrm{Hg}$ and $23 \mathrm{~mm} \mathrm{Hg}$; only in two patients did we measure extreme values: one patient with an IOP of $26 \mathrm{~mm} \mathrm{Hg}$ in left eye, another patient (designated DE) with an IOP of $12 \mathrm{~mm}$ $\mathrm{Hg}$ in right eye (with $21 \mathrm{~mm} \mathrm{Hg}$ in the left eye).

At the end of the study period, basically all eyes had an IOP reduction that was beyond what could have been achieved by latanoprost preservative free monotherapy (the one exception being - rather predictably - the right eye of DE which continued to have an IOP of $12 \mathrm{~mm} \mathrm{Hg}$ ). Six months after converting from mono- to combination therapy, the latanoprost-timolol fixed combination led to a mean reduction by 4.16 $\mathrm{mm} \mathrm{Hg}$ (SD: $2.33 \mathrm{~mm} \mathrm{Hg}, \mathrm{p}=0.816$ ); with the tafluprost-timolol fixed combination, the mean IOP was reduced by $5.38 \mathrm{~mm} \mathrm{Hg}$. In the latter case, the IOP reduction was statistically significant according to the 
Mann-Whitney-U-Test $(p=0,0345)$ Regarding safety and tolerability, no adverse events were reported in the tafluprost-timolol group, while at the end of the study period two patients treated with latanoprost-timolol requested a change in therapy because of local symptoms like burning, redness and foreign body sensation.

\section{Discussion}

Switching from antiglaucomatous monotherapy to fixed combination in the "real-world" of a routine ophthalmological practice led to a pronounced IOP reduction in our patients which was slightly more distinct under preservative-free tafluprost/timolol fixed-dose combination than under preservative-free latanoprost/timolol fixed-dose combination. At the end of the study period, all eyes had reached an IOP level considered to be "safe" - i.e. with glaucoma progression becoming unlikely. Our experience thus reflects the results of the VISIONARY study, in which 6 months after switching from latanoprost or timolol monotherapy to the tafluprost-timolol fixed combination, $69.2 \%$ showed an IOP reduction of $\geq 20 \%$, $53.6 \%$ of $\geq 25 \%$ and $40.0 \%$ of $\geq 30 \%$.(8)

When answering the questionnaire, the patients expressed their satisfaction both in terms of efficacy and tolerability of the drugs they applied and stressed the convenience of dealing with a fixed combination some of them had expressed concerns that they wouldn't be able to cope with several bottles in their daily lives.

\section{Conclusions}

Switching from prostaglandin monotherapy to a prostaglandin-timolol fixed combination led to a sufficient IOP lowering in our group of patients that seems to be fairly typical for "real-world" glaucoma patients and their problems. Tolerability of and satisfaction with the fixed combination was high.

\section{Abbreviations}

EGS European Glaucoma Society

IOP intraocular pressure

MIGS minimally-invasive glaucoma surgery

OHT ocular hypertension

POAG primary open-angle glaucoma

SD standard deviation

\section{Declarations}




\section{Ethics approval and consent to participate}

The Ethics Commission of the local university (Westfälische Wilhelms-Universität Münster) as well the regional medical board (Ärztekammer Westfalen-Lippe) have stated that there is no ethical concern about this retrospective study.

\section{Consent for publication}

Not applicable

\section{Availability of data and material}

Data are available from the corresponding author upon reasonable request.

\section{Competing Interests}

Ulrich Thelen has nothing to disclose.

\section{Funding}

No funding or sponsorship was received for this study or publication of this article.

\section{Author's Contributions}

Ulrich Thelen conceived the study design, performed the data analysis and wrote the first draft of the manuscript. He critically revised the manuscript.

\section{Acknowledgements}

Not applicable

\section{References}

1. Heijl A, Alm A, Bengtsson B et al (2012) The Glaucoma Guidelines of the Swedish Ophthalmological Society. Acta Ophthalmol 90:1-40

2. Alm A Latanoprost in the treatment of glaucoma.Clin Ophthalmol201; 8:1967-1985

3. Konstas AG (2020) Current and emerging fixed combination therapies in glaucoma: a safety and tolerability review. Expert Opin Drug Saf 19:1445-1460 
4. Shirai C, Matsuoka N, Nakazawa T (2021) Comparison of adherence between fixed and unfixed topical combination glaucoma therapies using Japanese healthcare/pharmacy claims database: a retrospective non-interventional cohort study. BMC Ophthalmol 21:52. doi: 10.1186/s12886-02101813-w

5. European Glaucoma Society, EGS 5th Edition (2020) Terminology and Guidance for Glaucoma https://www.eugs.org/eng/guidelines.asp

6. Xing Y, Zhu L, Zhang K et al (2020) The efficacy of the fixed combination of latanoprost and timolol versus other fixed combinations for primary open-angle glaucoma and ocular hypertension: A systematic review and meta-analysis. PLoS ONE 5(2):e0229682. doi: 10.1371/journal.pone.0229682

7. Hollo G, Katsanos A (2015) Safety and tolerability of the tafluprost/timolol fixed combination for the treatment of glaucoma. Expert Opin Drug Saf 14:609-617

8. Oddone F, Tanga L, Kothy P et al (2020) Treatment of Open-Angle Glaucoma and Ocular Hypertension with Preservative-Free Tafluprost/Timolol Fixed-Dose Combination Therapy: The VISIONARY Study. Adv Ther 37:1436-1451 